\title{
Editorial
}

\section{A robust and knowledgeable workforce is essential for public health nutrition policy implementation}

The issue of workforce development in public health nutrition is the hot topic in this issue of the journal. Training programmes in the area of public health nutrition are not that easy to identify in Europe, especially if you include quality criteria such as evidence-based learning, high-quality teaching staff, a good selection of core courses and a relevant and updated curriculum. Several training programmes in Europe have had to close down in the last decade, due to other priorities emerging in their respective universities.

In Europe, a wealth of policy documents are emerging on both nutrition and education, but the practical results in terms of implementation or evaluation are not impressive, at least according to the HOPE project ${ }^{(1)}$. Furthermore, according to this report, workforce development was rarely mentioned in these policies, and if a particular workforce was mentioned in relation to nutrition or obesity prevention, it was front-line staff such as those in health care or classroom teachers. In order to be effective, policies on nutrition and health should cover several jurisdictions including the ministry of education, not only (as is so often the case) those dealt with by the ministries of health and agriculture. A part of the solution would be to fully address a series of interconnected needs, to strengthen the workforce globally, to build strong networks, to identify core elements of training programmes, to provide a solid public health nutrition workforce to support front-line staff and to work towards a joint system for recognizing a knowledgeable, skilful and multidisciplinary public health nutrition workforce.

In this issue, we include several papers stemming from the JobNut project, which was performed as a part of the EU Leonardo programme in 2007 and 2008. This project was about identifying and supporting the role of the public health nutritionist in the European context. In the first paper, a framework developed by Roger Hughes and Barrie Margetts was further expanded following the end of the JobNut project, to become a useful model for public health nutrition practice ${ }^{(2)}$. The model identifies the involvement of intelligence gathering, action and the evaluation of the results in practical implementation of projects, policies and programmes. The second paper, by Susanna Kugelberg and colleagues, has a qualitative approach and is the result of an extensive process of interviewing stakeholders across Europe. The paper describes constraining and enabling factors for public health nutrition workforce development in seven European countries. The results evidence the lack of a supportive policy environment, a fragmented organizational structure for public health nutrition and the lack of a cohesive workforce to develop effective programmes ${ }^{(3)}$. The third paper describes the results of a Delphi study performed within the JobNut framework, looking at the core functions for the public health nutrition workforce in Europe and the consensus that was developed among European public health nutrition leaders ${ }^{(4)}$. An additional paper from this project, which was published in this journal last year, describes another Delphi study that reached consensus among public health nutrition leaders regarding the core competencies needed for public health nutritionists ${ }^{(5)}$. The fourth of the 'hot topic' papers, by Jennifer Davies and co-workers, again as a part of the JobNut project, looks at possibilities for building an international system of professional recognition for public health nutritionists ${ }^{(6)}$.

We have included two more workforce development papers in this issue. The first one, by Janet Cade and colleagues, looks at the British Register of Nutritionists, which is one of the very few systematic attempts to register nutritionists, and in this case includes public health nutritionists ${ }^{(7)}$. The paper by Kandelwal and co-workers maps nutrition teaching and training initiatives in India, indicating the gap in public health nutrition training ${ }^{(8)}$. Their analysis shows that public health nutrition is seldom taught at a high level in India: in only five out of 190 institutes. Considering the great need for action in India for public health nutrition and education, the paper is of considerable significance.

Within the next few years, we might be able to see a joint system for recognition of a competent workforce and qualified specialists in the area of public health nutrition. It is long overdue. We hear that ASPHER, the Association of Schools of Public Health in Europe, has set up its own accreditation system for education programmes in public health. We need to get our act together to describe the importance of a well-trained workforce on all levels, among policy makers, researchers, trainers and teachers, as well as in health-care front-line staff. The world needs to see a strong workforce in public health nutrition, with solid and consistent training programmes 
to fit. A shared identity and a solid training background are key factors to its success.

\author{
Agneta Yngve \\ Editor-in-Chief \\ Marilyn Tseng \\ Irja Haapala \\ Allison Hodge \\ Deputy Editors
}

\section{References}

1. Stockley L, Lynch C, Kugelberg S et al. (2009) National and Multinational Obesity Prevention Policies. Stockholm: Karolinska Institutet.

2. Hughes R \& Margetts B (2012) The public health nutrition intervention management bi-cycle: a model for training and practice improvement. Public Health Nutr 15, 1981-1988.
3. Kugelberg S, Jonsdottir S, Faxelid E et al. (2012) Public health nutrition workforce development in seven European countries: constraining and enabling factors. Public Health Nutr 15, 1989-1998.

4. Jonsdottir S, Thorsdottir I, Kugelberg S et al. (2012) Core functions for the public health nutrition workforce in Europe: a consensus study. Public Health Nutr 15, 1999-2004.

5. Jonsdottir S, Hughes R, Thorsdottir I et al. (2011) Consensus on the competencies required for public health nutrition workforce development in Europe - the JobNut project. Public Health Nutr 14, 1439-1449.

6. Davies J, Hughes R \& Margetts B (2012) Towards an international system of professional recognition for public health nutritionists: a feasibility study within the European Union. Public Health Nutr 15, 2005-2011.

7. Cade J, Eccles E, Hartwell $\mathrm{H}$ et al. (2012) The making of a nutrition professional: the Association for Nutrition register. Public Health Nutr 15, 2012-2019.

8. Khandelwal S, Dayal R, Jha M et al. (2012) Mapping of nutrition teaching and training initiatives in India: the need for Public Health Nutrition. Public Health Nutr 15, 2020-2025. 